\title{
PÉRDIDA DE EFICACIA DE LA CAUSAL DE NECESIDADES DE LA EMPRESA EN EL SISTEMA DE TERMINACIÓN DEL CONTRATO DE TRABAJO
}

\author{
MARIO VARAS CASTILLO* \\ Universidad Católica del Norte
}

\begin{abstract}
RESUMEN: El autor expone sobre el tratamiento, dado por la jurisprudencia, a la causal de necesidades de la empresa en el sistema de terminación del contrato de trabajo. A partir de un análisis que involucra un estudio técnico y de historia de la ley, entre otros, concluye que la recepción de la mencionada causal en la jurisprudencia la ha tornado ineficaz, por una interpretación restrictiva y excepcional de la misma.

Palabras clave: Procesos de modernización, necesidades de la empresa, terminación del contrato de trabajo, historia de la ley, jurisprudencia.

ABSTRACT: The author expose on the treatment given by the jurisprudence, to the grounds of business needs in the termination system of the employment contract. From an analysis involving a technical study and history of law, among others, he concludes that the reception of such grounds in the jurisprudence has turned ineffective, because the exceptionally narrow interpretation of it.
\end{abstract}

Key words: Termination of the employment contract, bussiness needs, labor law, history of law, jurisprudence.

\section{PLANTEAMIENTO DEL PROBLEMA}

Curioso el devenir histórico de la causal de necesidades de la empresa. Reinstalada el año 1990 dentro de nuestro sistema de terminación del contrato de trabajo con la entrada en vigencia de la Ley No 19.010, ha transitado a lo largo de veinte años por el campo laboral sin encontrar aún su lugar propio. En efecto, si por largo tiempo materializó una suerte de flexibilización de facto al devenir, por la falta de control jurisdiccional, en un verdadero libre despido con derecho a indemnización; hoy por hoy, frente a su cada vez más frecuente judicialización -como consecuencia de la nueva judicatura laboral-, ha evidenciado una progresiva pérdida de eficacia jurídica al consolidarse aquellos criterios jurisprudenciales que por años le han privado de ocupar el rol que el sistema jurídico le tenía asignado.

A nuestro entender, este fenómeno encuentra su origen en la orientación normativa pro empresarial que la causal ostenta, frente a un contexto de protección del trabajador inherente al Derecho del Trabajo. La historia de su establecimiento es concluyente en cuanto a que estaba llamada a convertirse en una importante herramienta de flexibilización y adaptabilidad laboral dentro del sistema nacional de terminación del contrato de trabajo, apostando a que los tribunales de justicia establecerían la correspondiente coordinación con el principio protector, en términos de amparar tanto la condición del trabajador, como los intereses de la empresa.

\footnotetext{
* Abogado, Universidad de Chile. Profesor de Derecho del Trabajo de la Universidad Católica del Norte, Sede Antofagasta. Contacto: mariovaras@gmail.com
} 
No obstante ello, nuestros tribunales lejos de promover dicha coordinación dentro del sistema de terminación, han consolidado progresivamente criterios de interpretación que han terminado por subordinar a la causal enteramente al Principio Protector, despojándola así en la práctica de toda relevancia.

En este orden de ideas, el presente trabajo pretende revisar la orientación normativa que dio origen a las necesidades de la empresa, así como los términos de su consagración literal y su concordancia con criterios de flexibilización pro empresarial que reconoce nuestra legislación laboral; para confrontarla con una jurisprudencia judicial, que a través de criterios que se apartan de las finalidades tenidas en consideración por el ordenamiento, han conducido a la causal a una gradual pérdida de eficacia.

\section{LA CAUSAL DE NECESIDADES DE LA EMPRESA COMO INSTRUMENTO DE FLEXIBILIZACIÓN LABORAL EN MATERIA DE TERMINACIÓN DEL CONTRATO DE TRABAJO}

Tal como lo hemos afirmado, la causal antes enunciada consagra dentro de nuestro sistema de terminación del contrato de trabajo, un instrumento de clara disposición empresarial a la hora de definir la plantilla laboral. Arribar a dicha conclusión es posible tanto del examen de la historia de su establecimiento, como del análisis de su tenor literal, y del hecho de participar de un conjunto de normas que miran al interés de la empresa dentro del Código del Trabajo; todo, según pasaremos a revisar.

\subsection{LA HISTORIA DE LA TRAMITACIÓN PARLAMENTARIA: ORIENTACIÓN NORMATIVA PRO EMPRESARIAL}

La incorporación de la causal de necesidades de la empresa dentro de nuestro sistema de terminación de contrato de trabajo, verificada en el año 1990 a la luz de la entrada en vigencia de la Ley No 19.010, materializó una clara orientación normativa tendiente a establecer una regulación que conciliase, por un lado, la debida protección del trabajador y, por otro, la imprescindible flexibilidad que requiere la empresa para adaptarse a las condiciones fluctuantes de la economía, en un contexto de fuerte competencia y de permanente incertidumbre en los mercados globales.

La finalidad de protección del trabajador que promovía el Mensaje del Ejecutivo, estaba intrínsecamente vinculada a la sustitución, por intermedio de esta causal, del libre despido contenido en el artículo 155 letra f) de la Ley No 18.620¹. Así, con su incorporación el legislador pretendía objetivar el régimen de despido, evitando el mero arbitrio patronal a través del reconocimiento de causas de despido vinculadas a los cambios en la economía, o en la organización de la empresa. En la misma perspectiva de resguardo, la reforma consensuó el aumento de las indemnizaciones por años de servicios en caso de término del contrato de trabajo, elevándolas de 150 días, a 330.

\footnotetext{
1 Al efecto, bien cabe tener presente que en el contexto de la legislación vigente a la fecha de tramitación del proyecto que terminaría por concretarse en la Ley No 19.010, la sola circunstancia de creación de la causal de necesidades de la empresa cumplió con un fin protector del trabajador, ya que por su intermedio se sustituyó el libre despido o desahucio como causal de aplicación general a todo trabajador.
} 
Por su parte, los requerimientos de flexibilización laboral para el empleador, se recogían por medio de una causal que le permitiría un manejo adecuado de la plantilla laboral frente a ciertas necesidades impostergables, como aquellas derivadas del cambio en las condiciones de mercado, o los permanentes procesos de reestructuración empresarial, que en la búsqueda de aumentar productividad y competitividad exigen ajustes en la dotación del personal ${ }^{2}$.

Así, por lo demás, lo manifestaba el propio Mensaje:

"El proyecto de ley vincula el término del contrato a una causa objetiva frente a la actual posibilidad de que el trabajador sea desahuciado unilateralmente sin fundamentación de tal medida, con la que se reviste de mayor dignidad a la relación laboral y la persona del trabajador...En segundo lugar, considera elevar las indemnizaciones asociadas al despido... Estos dos criterios aseguran razonablemente, dentro de las actuales condiciones de desarrollo de nuestra sociedad, una mayor dignidad del trabajador y mejor protección para el evento del despido. Al mismo tiempo resguardan la necesaria flexibilidad y autonomía que debe tener la gestión empresarial evitando mecanismos que impongan la inamovilidad, el reintegro obligatorio, o las autorizaciones previas para trabajadores sin fuero..." 3 .

De esta manera, para cumplir la finalidad propuesta, se optó por introducir una causal de terminación que autorizara el despido, respetando siempre la condición del trabajador, pero a la vez, dirigida especialmente a resguardar la debida flexibilidad que requieren las empresas para enfrentar cambios en las condiciones de mercado o derivadas de procesos de reestructuración organizacional.

En dicho sentido, la consagración de una figura de despido que pretendiese recoger elementos de flexibilidad laboral en nuestro ordenamiento jurídico, no constituía una excepción. Para bien o para mal, desde la dictación del DL No 2.200 en $1979^{4}$, nuestra legislación laboral comenzó a incorporar un conjunto de disposiciones de clara preeminencia patronal, las que si bien generaron impactos no menores en nuestro Derecho del Trabajo, ciertamente se integraron de manera más o menos sistemática -aunque no por ello menos compleja-, otorgándole a esta rama del Derecho una nueva función tendiente a resguardar los poderes del empresario.

Cabe recordar que este fin legislativo no es ajeno al Derecho del Trabajo. Entre otros autores, Lyon-Caen ${ }^{5}$ sostiene que esta rama del Derecho es una técnica que no sirve a una única función, sino que a una doble finalidad. Por una parte, consagrar derechos y beneficios a los trabajadores y, por otra, asegurar la capacidad de gestión al empresario. Por consiguiente, no debe extrañar, al menos en el plano doctrinal, que el Ejecutivo haya planteado estos fines al proponer la que a la postre se convertiría en la Ley No 19.010.

\footnotetext{
2 Originalmente la disposición contenía la falta de adecuación laboral o técnica del trabajador como justo motivo de despido, circunstancia que fue eliminada de la norma el año 2001, en el marco de la Ley No 19.759.

3 Disponible en www.bcn.cl/hisley/periodos? $\mathrm{p}=1990$

4 Parte integrante del denominado Plan Laboral.

5 LYON-CAEN, Gerard, “¿Derecho del Trabajo o Derecho del Empleo?”, En: Evolución del pensamiento iuslaboralista. Estudios en homenaje al profesor Héctor-Hugo Barbagelatta. Montevideo, Uruguay: Fundación Cultura Universitaria, 1997.
} 
Así por lo demás quedó de manifiesto en el curso de la tramitación parlamentaria. En efecto, diversas son las opiniones vertidas en el Senado y en la Cámara de Diputados, acerca de la finalidad perseguida con la causal de necesidades de la empresa, y el rol que estaba llamada a jugar dentro del sistema de terminación del contrato de trabajo.

Entre otros, el senador José Ruiz manifestaba: "con mucha responsabilidad política, intentó equilibrar las justas y largamente contenidas aspiraciones del mundo laboral con la necesidad imperiosa de no detener el desarrollo económico". Por su parte, el senador Calderón señaló que "al igual que la CUT y las organizaciones empresariales se declara, en general, partidario de una mayor flexibilidad en lo referente a la contratación y despido de la fuerza de trabajo”. A su turno, el entonces senador Piñera, expresaba: “...la única forma de lograr real estabilidad y dignidad en el empleo es... con una legislación laboral moderna y justa, que compatibilice las necesarias dignidad y estabilidades laborales con las igualmente necesarias flexibilidad y capacidad de adaptación a la economía”.

Así también, en la Cámara de Diputados se mantuvo una discusión concordante con el proyecto del Ejecutivo. Al respecto, el diputado Olivares manifestó que “... es fundamental que la legislación laboral se adecue a la nueva realidad, permitiendo así canalizar los conflictos en forma ordenada, sin perjudicar la marcha de la economía, evitando situaciones traumáticas... la regulación de los despidos debe respetar la necesaria flexibilidad de la empresa para acomodar su dotación de trabajadores ante los cambios en el entorno económico en que se desenvuelve; pero también debe resguardar la dignidad del trabajador, dándole protección frente a probadas arbitrariedades". Desde la misma perspectiva, el diputado Orpis afirmaba: “...en la relación laboral se deberá buscar la justa ecuación entre el fortalecimiento del derecho de gestión del propietario sobre su empresa y la debida protección y dignidad de los trabajadores".

De esta manera, desde el propio análisis de la historia fidedigna de la Ley No 19.010 es posible advertir que con ella, el Ejecutivo materializó un doble propósito. Por un lado, relevó el principio de protección al trabajador y, por otro, recogió otro criterio que a falta de denominación más precisa, se le ha llamado de flexibilización laboral, que adquiere por medio de esta causal una expresión particular en materia de terminación del contrato de trabajo.

En este orden de ideas y tratándose ambos de principios inherentes o incorporados en su evolución al Derecho del Trabajo, están llamados a interactuar coordinadamente, antes que en términos de competencia, correspondiéndoles a los intérpretes del Derecho, particularmente a los tribunales de justicia, promover la función que cada uno de ellos está llamado a jugar dentro del sistema.

\subsection{AnÁlisis literal del artículo 161 del Código del Trabajo}

En esta parte, analizaremos el tenor literal del artículo 161 del Código del Trabajo, el cual dispone en su inciso primero, lo siguiente: "Sin perjuicio de lo señalado en los artículos precedentes el empleador podrá poner término al contrato de trabajo invocando como causa las necesidades de la empresa, establecimiento o servicio, tales como las derivadas de la racionalización o modernización de los mismos, bajas en la productividad, cambios en las condiciones del mercado o de la economía, que hagan necesaria la separación de uno o más trabajadores". 
Previo a entrar al análisis en particular, es necesario hacer énfasis en la vinculación que la causal de necesidades de la empresa tiene con la ciencia económica. Gran parte de las expresiones en ella utilizadas, así como a las circunstancias o procesos a los que alude, nos remiten al ámbito económico y empresarial. En efecto, expresiones como modernización, racionalización, productividad, condiciones de mercado, tienden a encontrar un lugar más propicio de despliegue en la economía, la administración de empresas e ingeniería antes que en el Derecho. Esto nos habla a las claras, de la existencia de un primer punto de partida: la causal no puede ser entendida exclusivamente desde lo jurídico, sino que en su conceptualización debe necesariamente considerarse otros saberes relacionados fuertemente a la organización y dinámica empresarial.

En este contexto, nos parece oportuno detenernos a examinar qué debe entenderse por racionalización y modernización de una empresa ${ }^{6}$. Tales conceptos, ciertamente, no devienen del área jurídica, sino que se vinculan a la economía, la cual le asigna un contenido específico. Así por racionalización debemos comprender aquellas estrategias que se dirigen a organizar la empresa de tal modo que se obtengan los mejores resultados posibles con los menores costos o esfuerzos, en dicho sentido no puede ser sino entendida como una reestructuración organizativa que consiste, entre otros, en deshacerse de los procesos que no sean propios del giro, rediseñar los procesos básicos del negocio y efectuar cambios en la dirección y control de la producción; procesos estrechamente vinculados a políticas de desconcentración empresarial y de externalización ${ }^{7}$. Por modernización empresarial, debe entenderse la estrategia dirigida a la adopción de nuevos procesos de trabajos, también vinculados a reestructuración organizacional, y especialmente, hoy por hoy, a la innovación y adopción de nueva tecnología en el proceso productivo ${ }^{8}$.

Se desprende entonces, que para las ciencias económicas ambos conceptos se conciben intrínsecamente vinculados y como parte integrante de una misma estrategia empresarial que persigue objetivos de reducción de costos y de mayor competencia, especialmente para adquirir mayor capacidad operativa, a fin de responder a las fluctuaciones del mercado, y aumentar así su participación en él; en otras palabras, políticas diseñadas para obtener ventajas comparativas frente a la competencia?.

Hecha esta primera prevención y tal como es conocido por todos, el legislador no entregó una definición de necesidades de la empresa y, a su turno, ningún otro cuerpo normativo contiene algún concepto especial al cual remitirse. Sin perjuicio de ello, la propia disposición al identificar los casos que configuran necesidades de la empresa nos permite, por un lado, sostener que la causal estará motivada principalmente por situaciones derivadas de la economía, aun cuando, atendido su tenor, es evidente que pueden configurarla también

\footnotetext{
6 Nos parece pertinente detenernos en ellos antes que en las otras expresiones a que alude la causal, toda vez que productividad o condiciones de mercado, se presentan como términos de utilización y comprensión más corriente.

7 Olivera LOZANO, Guillermo, "Participación complementaria e integrada de la pequeña industria", en: Revista Comercio Exterior, México, 1997, pp. 8 y ss.

8 Collier, Xavier. La Empresa Flexible, Estudio sociológico del impacto de la flexibilidad en el proceso de trabajo. Madrid, España: Siglo XXI, 1997, pp. 17 y ss.

9 NOVICK, Martha, "La Transformación de la Organización del Trabajo". En: Tratado Latinoamericano de Sociología del Trabajo. México: Fondo de Cultura Económica, 2000, pp. 123 y ss.
} 
otras distintas. Tal como hemos afirmado antes, ya el propio artículo nos remite a políticas propias de reestructuración empresarial interna, o a procesos de modernización de procesos que no solo atañen a la incorporación de tecnología; en esta misma línea, bien podrían considerarse otras, tales como procesos de absorción empresarial motivados desde fuera de la empresa.

El punto es que en uno y otro caso, la doctrina está conteste en que las necesidades deben motivarse por consideraciones de carácter objetivas. Si bien el artículo no lo explicita de dicha manera, la historia de la tramitación de la ley da debida cuenta de ello; aun cuando no nos parece posible sostener que la objetivización de la causal exija sine qua non una prescindencia absoluta de voluntad del empleador en cuanto a las causas mismas de la desvinculación. Interpretarlo de dicha manera, supondría desconocer abiertamente que toda racionalización o modernización suponen por parte de la dirección de la empresa, una decisión positiva de obrar así.

En estas condiciones, la objetivización de la causal, si bien tratándose de circunstancias meramente económicas puede suponer la ausencia de voluntad del empleador; en el caso de procesos de reestructuración empresarial, debe entenderse como sinónima de fundamentación técnica. Por lo tanto, debe considerarse objetiva la aplicación de la causal de necesidades de la empresa no porque esta se genere con motivo de un hecho ajeno a la voluntad del empleador, sino que en tanto la decisión patronal adoptada exhiba una fundamentación de carácter técnica perfectamente constatable.

En esta perspectiva del análisis, también parece interesante detenerse en la expresión necesidades de la empresa, establecimiento o servicio. Tal como se desprende de su propia consagración legal, la causal no exige que las contingencias que justifican el despido afecten al conjunto de la empresa. Por el contrario, se alude conjuntamente a otras unidades menores de evidente connotación organizacional como lo son el establecimiento y el servicio. Tanto una y otra expresión se recogen, igualmente, a propósito de otras regulaciones en materia laboral, en donde siempre se les ha utilizado como designación de parcialidades o unidades menores que integran la empresa. Así, la expresión establecimiento aparece vinculada al Derecho Colectivo ${ }^{10}$; y servicio, se relaciona con materias propias de Derecho Individual $^{11}$.

Finalmente, parece también pertinente detenerse a examinar la palabra necesidad, utilizada por el legislador. Conforme al Diccionario de la Real Academia Española, esta significa "2. Todo aquello a lo cual es imposible sustraerse, faltar o resistir", y a su turno, la voz sustraerse se define como la acción de apartarse o separarse.

De ahí que sea posible sostener que cuando algo se hace por necesidad, se alude a todo aquello respecto de lo cual es imposible de sustraerse, faltar o resistir. Y en este orden de ideas, no es posible resistirse al despido de un trabajador, cuando por ello pasa la adaptación de la empresa a nuevas condiciones económicas más gravosas; o bien, cuando ello resulta imprescindible desde la perspectiva de un proceso de reestructuración empresarial.

10 Constitución de organizaciones sindicales (artículo 227, inciso 4\%), negociación colectiva (artículo 315 ).

11 Actividades exceptuadas de la aplicación del descanso en días domingo y festivos (artículo 38 número 2), feriado anual (artículo 67 inciso final), terminación del contrato por obra o faena (artículo 159 No5). 
Esta materia se vincula con algunos criterios que han querido concebir a las necesidades de la empresa como una suerte de herramienta de supervivencia de la organización frente a una crisis abierta que amenaza su continuidad. A la jurisprudencia de algunos tribunales que parecen irrogarle tal carácter a partir de la exigencia de gravedad y permanencia de las circunstancias en que se funda, se une cierta doctrina que identifica en la causal una suerte de protección a la empresa en su calidad de fuente de empleo ${ }^{12}$. En efecto, con su consagración el legislador sacrificaría a cierto número de trabajadores a cambio de mantener a la empresa como creadora de empleo y de riqueza. Si bien existen elementos importantes para visualizar en la causal también dicha orientación, a nuestro entender la misma se circunscribe más bien a criterios de flexibilización y de adaptabilidad laboral pro empresarial, de que participa nuestra legislación laboral y que en distintas materias se encuentran recogidos en nuestro Código, generando una matriz de regulación particular y coherente ${ }^{13}$.

Lo que el ordenamiento jurídico persigue, en consecuencia, es la materialización de la función que le ha asignado a la causal de permitir al empresario adaptar o reestructurar la organización al nuevo entorno, dentro de un contexto de protección del trabajador.

Protección que, parece importante recodarlo, a su vez se ve reforzada por tres instituciones concurrentes a propósito de la regulación de las necesidades de la empresa: el establecimiento de la causal en términos objetivos, el pago de indemnizaciones por su sola aplicación, y la sanción al despido injustificado, por medio de la siempre procedente judicialización y el subsecuente pago de recargos en caso de declararse injustificada.

En consecuencia, del análisis literal de la norma en comento es posible establecer los siguientes criterios de interpretación:

1) La expresión "tales como", hace referencia a que las circunstancias descritas en la norma legal son a mero título ejemplar, pudiendo verificarse otras distintas; por lo tanto la mención referida a "las derivadas de la racionalización o modernización de los mismos, bajas en la productividad, cambios en las condiciones del mercado o de la economía”, no es de carácter taxativa.

2) Resultan causas justificadas para su aplicación, aquellas derivadas de las bajas de productividad, cambios en las condiciones de mercado o de la economía; pero aún en el propio texto legal, estos fundamentos de naturaleza económica no son los únicos. Esta afirmación, que parece una perogrullada no es menor, toda vez que cierta jurisprudencia, tiende a considerar únicamente como necesidades de la empresa las derivadas de crisis económicas, subordinando incluso los procesos de reestructuración empresarial -racionalización y modernización- a estas contingencias, despreciando los que tienen su fuente en requerimientos meramente organizacionales.

3) La calidad objetiva de la causal, no debe interpretarse exclusivamente en cuanto a que la decisión de la desvinculación tenga su origen en hechos ajenos a la voluntad del empleador. Por el contrario, la objetividad debe vincularse a la existencia de

\footnotetext{
12 López Onetto, Marcos. "Flexibilidad Laboral Chilena y Principio de Protección de la Fuente del Empleo. Algunas Hipótesis”, en: Aportes al Debate Laboral No 8. Santiago, Chile: Publicación de la Dirección del Trabajo, 1999.

13 Cuestión que pone de manifiesto la complejidad de esta rama del Derecho, en donde coexisten en permanente tensión disposiciones que responden a los intereses de la empresa, como a la protección y dignidad del trabajador.
} 
antecedentes técnicos suficientes que justifiquen el ajuste de personal. La adecuada comprensión de las necesidades de la empresa motivadas por la racionalización o su modernización, exige dicha lectura toda vez que los procesos de reorganización empresarial, no siempre vienen impulsados por crisis de mercado, sino que la mayor parte de las veces responden a planificaciones inherentes a la empresa, en función de aumentos de productividad y competitividad.

4) Por su parte, el artículo 161 en su inciso primero, se refiere a las necesidades de la "empresa, establecimiento o servicio"; por lo tanto se desprende que las necesidades -sean cuales fueran estas-, no exigen que afecten a la totalidad de la organización, sino que pueden perfectamente centrarse en una parte de ella, sea un establecimiento, o aún un servicio específico en que se haga necesario el ajuste de dotación.

5) Resulta absurdo homologar la aplicación de la causal de necesidades de la empresa a su virtual quiebra o insolvencia. Es obvio que en tal crítica situación no cabrían ya medidas destinadas a lograr un imposible buen funcionamiento de la empresa, sino que sería el momento de solicitar simplemente su cierre.

Tal como es posible observar, los términos de consagración legal de la causal de necesidades de la empresa, son absolutamente concordantes con las finalidades perseguidas por el legislador al incorporarla a nuestro sistema de terminación del contrato de trabajo. Lo anterior, sin duda, se ve reforzado cuando advertimos que la causal en sí, participa de aquellos criterios de flexibilización laboral incorporados a nuestra legislación laboral.

\subsection{FleXibILIDAD LABORAL EN EL CÓDigO DEL TRABAJO}

Llegados a este punto, es importante considerar que la causal también encuentra su vinculación con otras figuras o instituciones presentes en nuestra legislación laboral, que recogen en el contexto de la normativa protectora del trabajador, disposiciones que otorgan importantes grados de preeminencia al empleador dentro de la relación laboral, con el objeto de que su gestión no se rigidice en exceso.

Así, entre otras normas, identificamos en materia de contratación, aquellos denominados contratos de corta duración (artículo 44, inciso 40), así como el contrato a tiempo parcial (artículo 40 bis y ss); la polifuncionalidad (artículo No3); el ius variandi (de los artículos 12, 24, 29 y 89); en materia de jornada de trabajo la posibilidad de distribuir jornada de trabajo en días domingo y festivos (artículo 38); en materia de feriado anual, la intervención del empleador en la determinación de la oportunidad de ejercicio del derecho a vacaciones (artículo 67, inciso final); en cuanto a la determinación de la estructura remuneracional, en donde es reconocida la amplia flexibilidad al empleador para establecerla; etc.

Como es posible observar, la causal de necesidades de la empresa no es una disposición aislada o ajena en nuestro ordenamiento laboral, sino que por el contrario se circunscribe dentro de un contexto de regulación que recoge facultades no menores al empleador para determinar en forma importante el contenido mismo de la relación laboral. Dicho en otras palabras es posible reconocer en nuestro Código del Trabajo un corpus más o menos sistemático de regulación pro empresarial que tiene su correlato de expresión en todas aquellas materias propias del Derecho Individual. Lógico resulta entonces, que este criterio pre- 
valeciente ostente un correlato de expresión dentro del sistema de terminación del contrato de trabajo, máxime si se considera que precisamente la orientación normativa al integrar la causal de necesidades de la empresa fue resguardar "la necesaria flexibilidad y autonomía que debe tener la gestión empresarial evitando mecanismos que impongan la inamovilidad, el reintegro obligatorio, o las autorizaciones previas para trabajadores sin fuero...”.

La existencia de este tipo de normas, hacen manifiesta la complejidad propia del Derecho del Trabajo y su inherente ambivalencia funcional ${ }^{14}$. En efecto, desde los orígenes históricos de la rama ha estado presente este tumultuoso equilibrio entre la protección del trabajador y la preservación del orden económico. Transcurridos más de cien años, aún dicha matriz no puede ser superada y, de tanto en tanto, de la mano de los cambios de época, esta dicotomía adquiere distintas expresiones. Actualmente, sin embargo, diversas posiciones reclaman el establecimiento de "mecanismos de armonización entre las garantías protectoras... y los mayores espacios de libertad que reclama la actual relación que se da en el mundo de la empresa"15.

En resumen, puede afirmarse que tanto la orientación normativa de la consagración de la causal, la redacción de la disposición que la contiene, así como la existencia de un grupo de normas de clara preeminencia patronal en nuestro Código del Trabajo, vinculada a criterios de flexibilidad y adaptabilidad laboral, conducen a concluir que la causal de necesidades de la empresa, contenida en el artículo 161 del Código del Trabajo, ostenta una finalidad bien clara y precisa y que no es otra más que resguardar los intereses de la empresa en materia de terminación del contrato de trabajo.

\section{LOS PRINCIPALES CRITERIOS JURISPRUDENCIALES APLICADOS A LA CAUSAL DE NECESIDADES DE LA EMPRESA}

Según hemos revisado, la consagración de la causal objeto de estudio obedeció al interés del legislador por establecer una causal de terminación del contrato de trabajo que permitiese conciliar los permanentes requerimientos de adaptabilidad y flexibilidad para las empresas, con el principio protector del trabajador inherente al Derecho del Trabajo.

En estas condiciones, correspondía a los tribunales de justicia establecer la debida interpretación de la causal, asegurando su necesaria eficacia jurídica sobre la base de la coordinación de los intereses normativos previstos.

A nuestro entender y muy por el contrario, los tribunales lejos de promover tal equilibrio, han terminado por asentar criterios jurisprudenciales que únicamente tienden a subordinar a las necesidades de la empresa al principio protector, desconociendo, por tanto, los requerimientos de flexibilización laboral que la misma persigue, materializando con ello una progresiva pérdida de su eficacia jurídica.

Esta tendencia que ya se evidenciaba en la jurisprudencia previa a la reforma laboral,

\footnotetext{
14 Ver, entre otros, UgarTe, José Luis. "La Función del Derecho del Trabajo, entre la Economía y la Política”, en: Revista Laboral Chilena, 2003.

15 Humeres, Héctor. "Reflexiones en relación a algunos aspectos del Derecho Laboral vinculados al desarrollo futuro de la empresa". En: Estudios en Homenaje al profesor William Thayer. Santiago, Chile: Sociedad Chilena de Derecho del Trabajo, 1998 , p. 115.
} 
con la entrada en vigencia de esta y la creciente judicialización de la causal de terminación, no ha terminado más que por consolidarse, rigidizando el sistema de terminación del contrato de trabajo.

Revisemos entonces, los principales criterios jurisprudenciales prevalecientes:

\subsection{LAS NECESIDADES DE LA EMPRESA COMO CAUSAL OBJETIVA: CIRCUNSTANCIAS AJENAS A LA VOLUNTAD DEL EMPLEADOR}

Tal como afirmáramos, uno de los criterios asentados es el carácter objetivo de la causal de necesidades de la empresa, cuestión que por lo demás está en concordancia con la orientación normativa que le dio origen; no obstante ello, nuestros tribunales han homologado esta condición a la ausencia absoluta de voluntad del empleador en cuanto a las causas que originan la desvinculación, cuestión que a la postre ha impedido la aplicación de la misma, en los siguientes casos:

a) Cuando las negativas circunstancias económicas que justifican su aplicación, se derivan de hechos imputables al empleador;

b) Cuando la modernización o racionalización son introducidas por mero requerimiento empresarial, sin estar motivadas por hechos externos a la empresa.

Así, entre otros, lo establece la Corte de Apelaciones de Chillán, en fallo de 11 de agosto de 2006, pronunciado en autos Rol No 65-2006: "Que la causal de necesidades de la empresa está contemplada como una causal de término de contrato de trabajo objetiva, por lo que para que pueda ser invocada por el empleador es necesaria la concurrencia de ciertos hechos o situaciones que la hagan precedente, no dependiendo de su mera voluntad...”.

En el mismo sentido, la Corte de Apelaciones de Iquique, en sentencia de 15 de diciembre de 2009, en autos Rol No 93-09:

"Segundo: ...que los aspectos de orden económico que podrían afectar a la empresa y que la habilitarían para invocar la causal de necesidades de la empresa, deben importar, en general, la existencia de un deterioro en las condiciones económicas de la misma, que haga inseguro su funcionamiento, conclusión que no es aplicable en la especie, por cuanto una empresa del Estado, como la demandada, no podría encontrarse nunca en una situación de inseguridad en su funcionamiento, ni caer en insolvencia, ni ser declarada en quiebra, por el carácter que detenta, de modo que el argumento del sentenciador debía ser otro".

El mismo criterio prevalece en la decisión de Corte de Apelaciones de Santiago, que en resolución de fecha 30 de marzo de 1999, en autos Rol No 3.946-98, señaló:

"7o: Que, a mayor abundamiento, el exceso de costos operacionales de naturaleza laboral que habría derivado en una sobredotación de personal asignado para la ejecución de de un determinado proyecto por la empleadora -hecho que se esgrime como causa originaria del despido del actor-, debió tener como causas directas las propias 
decisiones de la empleadora, y, por tanto, a esta únicamente le son imputables esos hechos, que habrían motivado la terminación anticipada del contrato de trabajo del actor, el que, por todo lo expuesto, ha de calificarse como injustificada".

Siguiendo el mismo criterio se pronuncia el Primer Juzgado del Trabajo de Santiago, en sentencia de 19 de noviembre de 2009, recaída en autos O-43-2009:

"Duodécimo: ...Tales hechos deben ser analizados desde la óptica de la causal de necesidades de la empresa, invocada al despedir a la actora. Si bien la norma del artículo 161 no establece en forma taxativa en qué consisten las necesidades de la empresa, establecimiento o servicio, sí otorga una pauta mencionando algunos ejemplos, como las derivadas de la racionalización o modernización de los mismos, bajas en la productividad, cambios en las condiciones del mercado o de la economía, que hagan necesaria la separación de uno o más trabajadores. Esa mención de casos en que se verifica la causal en comento permite colegir que debe tratarse de situaciones objetivas, independientes de la voluntad de las partes, en que se producen situaciones propias de la actividad económica de que se trata, respecto de las cuales la empresa debe hacer frente, y dentro de las posibilidades de enfrentarla se hace necesario prescindir de un trabajador.

Finalmente, la Excelentísima Corte Suprema, en fallo de fecha 12 de noviembre de 2008, en autos Rol No 544-08, estableció:

"Quinto: Que... como lo ha señalado anteriormente esta Corte y lo destacan los sentenciadores, si bien los casos contemplados en él no son de carácter taxativo, es decir, la disposición puede alcanzar a situaciones análogas o semejantes, todas ellas siempre deben decir relación con aspectos de carácter técnico o de orden económico. Los primeros aluden a rasgos estructurales de instalación de la empresa, que provocan cambios en la mecánica funcional de la misma. En cuanto a los segundos, ellos importan -en general-, la existencia de un deterioro en las condiciones económicas de la empresa que haga inseguro su funcionamiento.

Sexto: Que por otro lado cabe considerar que tratándose de una causal de despido objetiva, ajena entonces a la conducta contractual o personal del dependiente y que excede, por cierto, la mera voluntad del empleador, requiere, en todo caso, la concurrencia de hechos o circunstancias que la hagan procedente..”.

A nuestro entender, darle la connotación que le atribuyen los tribunales de justicia al carácter objetivo de la causal, además de incorporar elementos no previstos en el tenor mismo de la disposición, afecta su orientación normativa que más bien dirige la objetivización de la norma hacia la existencia de fundamentos técnicos reales que la justifiquen. Homologar "objetividad" con "ausencia de voluntad patronal" implica vaciar de contenido técnico a una causal que precisamente encuentra su sentido en los requerimientos inherentes a la administración de empresas como ciencia y área de experiencia humana particular. 


\subsection{LAS NECESIDADES DE LA EMPRESA, COMO UNA CAUSAL GRAVE Y PERMANENTE: EL RE- QUERIMIENTO IMPLÍCITO DE LA CRISIS DECLARADA AL INTERIOR DE LA ORGANIZACIÓN COMO CONDICIÓN DE SU PROCEDENCIA}

Otro criterio, vastamente compartido por la jurisprudencia judicial es aquel que identifica la aplicación de las necesidades de la empresa a una situación de crisis económica insubsanable; esto es, prácticamente terminal para la organización. Esta conclusión repugna por sí sola su espíritu, por cuanto esta persigue generar adaptación para la empresa frente a escenarios económicos complejos, o procesos de reestructuración impostergables, que no implican inevitablemente su insolvencia o quiebra.

Este criterio, ha llevado a una imposibilidad de aplicación de la causal en eventos como:

a) Ante resultados negativos de la empresa que siendo relevantes, no revisten condiciones suficientes para ser tenidos por insubsanables, aun cuando igualmente exijan un ajuste de personal;

b) Requerimientos técnicos u organizacionales focalizados en servicios o establecimientos de una empresa, que afectan solo a la unidad, pero no a la empresa en su conjunto.

En este sentido, entre otros, se ha pronunciado la Corte de Apelaciones de Santiago, en sentencia de 31 de marzo de 2011, recaída en autos Rol No 3468-10:

“3.- Que, primeramente, la quiebra de la empresa de manera alguna configura algunas de las hipótesis a las que se alude en el Art. 161 del Código del Trabajo para justificar el despido de un trabajador por necesidades de la empresa, que si bien no son taxativas no lo es menos que si se le quiere fundar en cualquier otro hecho que no sea de los descritos en esa norma legal debe en todo caso ser claramente especificado en el aviso de despido pertinente. Enseguida, la quiebra es la situación en que queda una empresa por un hecho no imputable al trabajador. Generalmente se produce por una deficiente administración del empresario o por causales externas a la empresa que rebasan el ámbito de lo laboral para caer en lo estrictamente económico y comercial en donde al trabajador no le cabe injerencia alguna. A esto debe agregarse que la causal de despido invocada al demandante supone que la empresa se encuentra en funcionamiento y actividad al momento en que se hace efectivo dicho despido, lo que obviamente no sucede si la empresa fue declarada en falencia."

Comparte el criterio la Corte de Apelaciones de Antofagasta, en fallo de 25 de septiembre de 2009, autos Rol No: 154-09:

"Cuarto: ... debiendo destacarse que para el uso de esta (la causal de necesidades de la empresa) el trabajador debe recibir una razón objetiva de su despido, recayendo sobre el empleador el gravamen procesal del peso de la prueba, quien deberá acreditar que concurren en la especie los supuestos fácticos objetivos que la hagan procedente, esto es, deben revestir el carácter de graves y permanentes para que opere la causal, 
independiente de la voluntad de las partes y concerniente a situaciones económicas o tecnológicas".

La Corte de Apelaciones de Chillán, en fallo de 23 de noviembre de 2009, pronunciado en autos Rol No 20-2009, sostuvo:

“3.- Que la jurisprudencia ha señalado que el legislador contempla en la indicada disposición legal diversas hipótesis de aplicación de la causal... Las hipótesis descritas tienen en común los elementos de la ajenidad u objetividad, gravedad y permanencia. Si se comparan las hipótesis indicadas, el carácter económico o tecnológico de las necesidades de la empresa está latente en cada una de estas, lo que constituye un faro en la búsqueda de la medida que debe ser usada como referencia en la precisión de lo que debe entenderse por necesidades de la empresa...".

Criterio que la misma Corte de Apelaciones de Antofagasta ratificó en otro fallo, de 8 de noviembre de 2010, recaído en autos Rol No 98-2010:

"Cuarto: Que en cuanto a la causal invocada para poner término al contrato de trabajo, el artículo 161 del Código del ramo, esto es, "necesidades de la empresa, establecimiento o servicio", esta, es de carácter objetiva, independiente de la voluntad de las partes y dice relación exclusivamente con circunstancias que rodean la actividad económica de que se trata. Los casos contemplados en la ley apuntan a circunstancias económicas o tecnológicas. Para su configuración es necesario que las circunstancias no emanen de la sola voluntad o responsabilidad de la empresa, de modo que estas deben ser objetivas, graves y permanentes. Los problemas económicos de la empresa no deben ser transitorios y subsanables.

Siguiendo la misma orientación, se pronunció la Corte de Apelaciones de La Serena, en sentencia de 21 de marzo de 2011, autos Rol 2-11:

“ ...Por otra parte, y no obstante que el representante de la Sociedad..., Síndico de Quiebras, fundamenta el despido en las necesidades de la empresa, artículo 161 del Código del Trabajo, según se desprende de las cartas aviso de cesación de servicios..., documentos en los cuales se explicita, "basado en el hecho de la declaración de la quiebra previamente señalada, y la imposibilidad legal de proseguir con las actividades productivas de la fallida”, no produjo ninguna prueba ni acompañó antecedentes para demostrar la imposibilidad de continuar con el giro total o parcial de las actividades del fallido, posibilidad que... excluye la situación fáctica invocada, imposibilidad legal de proseguir con las actividades productivas por lo que no se condice con la hipótesis prevista en la norma legal citada -artículo 161 del Código del Trabajo-, lo que lleva a concluir a estos sentenciadores que no se ajusta a derecho la causal invocada...”.

En el mismo sentido concluyó la Corte de Apelaciones de Concepción, en fallo de 9 de julio de 2007, autos Rol No 3717-06, que señaló: 
"17. Que no puede soslayarse, que no obstante las pérdidas registradas por la empresa demandada en sus ejercicios anuales, esta fue vendida originando un cambio de propietarios, conforme se indica en el escrito de contestación de la demanda, lo cual autoriza concluir según reglas de lógica y experiencia, que la empresa no se encontraba afecta a problemas económicos irremediables, por cuanto no es normal que los empresarios adquieran empresas carentes de futuro financiero".

Finalmente, el Primer Juzgado del Trabajo de Santiago, en sentencia de 19 de noviembre de 2009, recaída en autos O-43-2009:

"Duodécimo: ...Así entonces, si bien es posible, en este caso, concluir que la demandada se vio enfrentada a una merma presupuestaria por no haberse adjudicado los concursos que se habían proyectado y por los mayores desembolsos en que incurriría en cumplimiento de los contratos colectivos suscritos con sus trabajadores, no es menos cierto que ello no puede entenderse ligado a las variables propias del mercado en que la empresa desarrolla su giro, puesto que, en el primer caso, se trata de descoordinaciones internas, ...mientras que en la segunda situación aparece insostenible la afirmación de que se hace necesario despedir trabajadores para dar cumplimiento a un contrato colectivo".

\subsection{LAS NECESIDADES DE LA EMPRESA, COMO UNA CAUSAL FUNDAMENTALMENTE ECO- NÓMICA: IRRELEVANCIA DE LOS PROCESOS DE MODERNIZACIÓN O RACIONALIZA- CIÓN COMO CONSTITUTIVOS DE DESPIDO JUSTO}

En fallo de la Corte Suprema, de 22 de diciembre de 2009, autos Rol No 7022-09, es posible advertir cómo a criterio del tribunal la causal de necesidades de la empresa exige para su procedencia que los procesos de modernización o racionalización estén sustentados en una situación económica grave, aun cuando -tal como señaláramos- tratándose de reestructuraciones organizacionales la disposición legal no alude a ello:

"Decimocuarto: Que, así, el costo de la decisión de transformarse, fusionarse y modificar la modalidad de prestación de sus servicios en virtud de cuyo diseño se justificaba la contratación de los actores, cuando ella no ha sido ocasionada por razones de bajas de productividad o que involucren en sí merma en las condiciones económicas del empleador, no puede ser traspasado al dependiente, por cuanto -como se ha dicho- el legislador laboral protege la estabilidad en el empleo y la mantención de las fuentes laborales, siendo de carga del empleador la indemnización de sus trabajadores con los incrementos que al efecto dispone la ley, siempre que la empresa no se encuentre en la necesidad de prescindir de sus empleados por una situación externa e independiente de ella, sino que la misma ha sido generada por su decisión libre, en pro de la optimización de sus recursos y funcionamiento, decisión legitima que la ley no objeta pero cuyas consecuencias deben ser asumidas por el titular de la misma”. 
Este fallo resulta particularmente interesante en la parte final del considerando, por cuanto el mismo parece desconocer que las necesidades de la empresa lleva implícito el pago de indemnizaciones por término de contrato; razón por la cual el empleador invocándola no pretende sustraerse de dicha obligación. Este elemento no es menor, por cuanto es posible observar de diversos fallos que el tratamiento que los tribunales hacen de la causal es idéntico de aquellas que al ser invocadas no conllevan el pago de indemnizaciones; en cuyo evento es comprensible que la jurisprudencia exija criterios más rígidos de procedencia; pero no así respecto de esta causa de terminación que en el afán protector impreso por el propio legislador, fue establecida reconociéndose al trabajador el pago de las indemnizaciones por término de contrato del artículo 162, inciso $4^{\circ}$, en su caso y artículo 163 , ambas del Código del trabajo.

Desde otra perspectiva, cabe destacar del fallo en comento que así también se desprende de él que aún "la optimización de recursos y funcionamiento"-elementos sobre los cuales está concebidamente particularmente la procedencia de la causal de necesidades de la empresa-, aparecen como insuficientes para estimar justificada su aplicación. No se comprende entonces en qué condiciones sí lo sería.

Por su lado, la Corte de Apelaciones de Coyhaique, en fallo de 16 de mayo de 2009, recaído en autos Rol No 16-09 se pronunció en términos semejantes:

"Quinto: ...puesto que no basta que se invoquen las necesidades de la empresa, sino que es necesario que, la 'racionalización' y 'reestructuración' en que aquella pretende sustentarse, se funden en hechos objetivos, resultando insuficiente para tales fines que se diga que la empresa demandada se fusionó con aquella, y las tareas que desempeñaban los trabajadores de la última se externalizaron, contratándose en su reemplazo a una empresa subcontratista. A juicio de estos sentenciadores, no basta que se informe que la empresa se fusionó y habrá racionalización y reestructuración, sino que deberá probarse cuáles son los motivos por los cuales a raíz de esta nueva situación suya, se estimó necesario despedir a la demandante, y por aquellos además se concluya, que ha resultado inevitable para el empleador despedirla...".

\section{OBSERVACIÓN FINAL: DEMANDANDO RESPUESTAS COMPLEJAS}

Tal como hemos podido advertir, la jurisprudencia de nuestros tribunales lejos de promover una interpretación de la causal de necesidades de la empresa concordante con los criterios legislativos implícitos en su consagración -como instrumento patronal para posibilitar el despido dentro de un contexto de flexibilización y adaptabilidad laboral-, ha terminado por subordinarla enteramente al principio protector.

En efecto, concebir la validez de la causal fundada únicamente en circunstancias "objetivas, graves y permanentes", las que, a su turno, "no deben ser transitorias y subsanables"; ha motivado en la práctica la imposibilidad de que las necesidades de la empresa se desplieguen adecuadamente, al punto de ser, hoy por hoy, escasos - por no decir marginales-, aquellos casos en que su aplicación ha sido estimada legítima. 
A juicio de muchos, la jurisprudencia asentada por los tribunales no podría ser otra. Confrontada esta causal de clara preeminencia empresarial frente al principio protector, lógico resulta que a esta se le termine por desconocer espacios de aplicación al punto, incluso, de perder toda eficacia. En tal sentido -se nos dirá-, los tribunales no han hecho más que asegurar la primacía de los principios propios del Derecho del Trabajo y la función protectora del trabajador que este está llamado a ejecutar.

No obstante ello, nos parece que tal solución, siguiendo a Goldin ${ }^{16}$, es demasiado simple. El Derecho del Trabajo, en cuanto Derecho Social no es pacífico y bien el mismo puede ser considerado un territorio en disputa. Su doble funcionalidad, de protección del trabajador y su dignidad, por un lado, y de legitimación del orden económico prevaleciente, expresado en la libertad de empresa y el poder del empresario, del otro; demandan equilibrios estructurales de carácter complejo. En tal perspectiva, a los intérpretes y agentes laborales les corresponde proveer respuestas matizadas y plurales; en donde, finalmente, se asegure la eficacia de todas y cada una de las instituciones y figuras establecidas en nuestra normativa laboral.

Tal debería ser entonces el rol de nuestros tribunales, reconocer la complejidad que resulta intrínseca al Derecho del Trabajo para proveer soluciones de coordinación, entre regulaciones que estando insertas en un mismo ordenamiento, promueven soluciones o tutelas distintas, en tanto responden también a intereses contrapuestos. Por el contrario, no parece adecuado promover soluciones que en términos prácticos supongan la pérdida de eficacia de ciertas normas, por cuanto dicha posición no redundará más que en una suerte de derogación promovida por vía judicial.

Y esta cuestión no es menor, por cuanto, finalmente, tal rol corresponde exclusivamente al Legislativo, el que por medio de la ley, entendida esta como expresión de la voluntad soberana de una nación, y a través de los consensos políticos necesarios, corresponderá introducir aquellas modificaciones que se estimen pertinentes para eliminar normas que puedan considerarse reñidas con principios jurídicos superiores.

En tanto dicho ejercicio democrático no se materialice, bien se podría, en el intertanto, asegurar que las normas existentes en nuestro ordenamiento laboral se desplieguen garantizando su plena eficacia en equilibrio con otras disposiciones, aun cuando estas obedezcan a intereses diversos. Finalmente, el Derecho del Trabajo no resolverá las tensiones que le son propias, sino que adentrándose en la complejidad en que se ha sostenido desde siempre.

\section{BIBLIOGRAFÍA}

Collier, Xavier. La Empresa Flexible, Estudio sociológico del impacto de la flexibilidad en el proceso de trabajo. Madrid, España: Siglo XXI, 1997.

Goldin, Adrián. Las tendencias de transformación del Derecho del Trabajo (Hipótesis sobre un Destino Complejo). Disponible en: www.udesa.edu.ar/files/UAhumanidades/DT/DT29-A.pdf

16 Goldin, Adrián. Las tendencias de transformación del Derecho del Trabajo (Hipótesis sobre un Destino Complejo). Disponible en: www.udesa.edu.ar/files/UAhumanidades/DT/DT29-A.pdf 
HUMERES, Héctor. "Reflexiones en relación a algunos aspectos del Derecho Laboral vinculados al desarrollo futuro de la empresa”. En: Estudios en Homenaje al profesor William Thayer. Santiago, Chile: Sociedad Chilena de Derecho del Trabajo, 1998.

LYON-CAEN, Gerard. “¿Derecho del Trabajo o Derecho del Empleo?”, En: Evolución del pensamiento iuslaboralista. Estudios en homenaje al profesor Héctor-Hugo Barbagelatta. Montevideo, Uruguay: Fundación Cultura Universitaria, 1997.

López Onetto, Marcos. "Flexibilidad Laboral Chilena y Principio de Protección de la Fuente del Empleo. Algunas Hipótesis”, en: Aportes al Debate Laboral No 8. Santiago, Chile: Publicación de la Dirección del Trabajo, 1999.

NovicK, Martha. "La Transformación de la Organización del Trabajo". En: Tratado Latinoamericano de Sociología del Trabajo. México: Fondo de Cultura Económica, 2000.

ERMIDA, Óscar. "La Flexibilidad en algunas experiencias comparadas”. En: TAPIA, Francisco; ERMIDA, Óscar y RomagnOLLI, Umberto. Experiencias de flexibilidad normativa. Las transformaciones del derecho del trabajo. Santiago, Chile: Universidad Nacional Andrés Bello, 1992.

Olivera LOZANO, Guillermo. "Participación complementaria e integrada de la pequeña industria", en: Revista Comercio Exterior, México, 1997.

UGARTE, José Luis. "La Función del Derecho del Trabajo, entre la Economía y la Política”, en: Revista Laboral Chilena, 2003. 